\title{
Filigrane
}

Écoutes psychothérapiques

\section{Adieu Oedipe ; bonjour Narcisse ? Mise à jour des réflexions sur l'utilisation clinique de la théorie oedipienne}

\section{Le comité de rédaction}

Volume 17, numéro 2, automne 2008

L’avenir du clinicien II

URI : https://id.erudit.org/iderudit/019429ar

DOI : https://doi.org/10.7202/019429ar

Aller au sommaire du numéro

Éditeur(s)

Revue Santé mentale au Québec

ISSN

1192-1412 (imprimé)

1911-4656 (numérique)

Découvrir la revue

Citer ce document

Le comité de rédaction (2008). Adieu Oedipe ; bonjour Narcisse ? Mise à jour des réflexions sur l'utilisation clinique de la théorie oedipienne. Filigrane, 17(2), 197-198. https://doi.org/10.7202/019429ar 


\section{Adieu OEdipe; bonjour Narcisse? Mise à jour des réflexions sur I'utilisation clinique de la théorie œdipienne. Argumentaire des dossiers 2010 de Filigrane}

le comité de rédaction

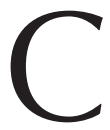

omment articuler le complexe d'CEdipe aujourd'hui ? Demeure-t-il toujours une fonction structurante de la psyché? Le temps serait-il venu d'abandonner ce concept théorique? En effet, la biotechnologie permet maintenant de contourner le roc du biologique et de changer le destin des infertilités hétérosexuelle et homoparentale, ainsi que de dissocier sexualité, procréation et famille. Quels sont les impacts de ces manipulations qui, sur la scène externe répondent aux demandes de l'adulte mais, sur la scène interne, rencontrent sa toute-puissance narcissique et ses fantasmes sexuels infantiles? Pouvons-nous percevoir l'impact psychique des changements rendus possibles par la technologie médicale sur l'économie psychique du sexuel, sur la conflictualisation, le deuil, le temps nécessaire à l'élaboration psychique ? Sommes-nous en train de contourner le roc du biologique, des infertilités tant hétérosexuelle qu'homoparentale et, partant, de régler - ou d'éluder - la troublante question du féminin?

Par ailleurs, au niveau social, la famille nucléaire éclatée, le triangle œdipien semble en voie d'être remplacé par d'autres formes géométriques: duo enfantparent divorcé, redoublement d'un même sexe parental, solo d'un géniteur anonyme ou mis entre parenthèse, quadrature des couples grands-parentaux. L'enfantroi, ne régnant sur rien, ne devient-il pas de plus en plus souvent l'objet narcissique du parent? Quel roman familial cet enfant sera-t-il contraint d'élaborer? Quel travail psychique exige de l'enfant le fait d'avoir, par exemple, deux parents du même sexe, quatre parents (deux biologiques et deux adoptifs), une mère adoptive qui allaite, une présentation du sexuel ramenant les orientations hétérosexuelle, homosexuelle, bisexuelle à une question de simple choix entre des réalités équivalentes dénuées de conflictualités intrinsèques? De quel travail psychique les adultes font-ils ainsi eux-mêmes l'économie? 
Comment se gère intrapsychiquement l'actuelle hypersexualisation de la jeunesse sur la scène sociale, cette mise en berne de la période de latence et de l'élaboration de la bisexualité psychique? Comment se débrouille Edipe et son surmoi avec l'invitation à une pratique précoce de la sexualité ? Si la culpabilité consciente liée à la transgression ne semble plus avoir de raisons d'exister, quels sont les effets intrapsychiques de sa disparition? Quelle fantasmatique inconsciente est sollicitée chez les parents motivant leur incapacité à mettre des limites ?

Par ailleurs, que penser du fait que les institutions psychanalytiques relèguent souvent, en pratique, les théories du pulsionnel derrière celles du narcissisme et des relations d'objet dans la formation de leurs candidats?

Des cliniciens continuent pourtant de rapporter la présence de structures œdipiennes chez des enfants élevés au sein de nouvelles configurations familiales (enfants adoptés à la naissance par des couples homosexuels, par exemple). D'autres cliniciens font part d'une utilisation féconde des topiques freudiennes pour analyser le nouveau matériel apporté par leurs patients, ne serait-ce que pour interroger les conséquences du retrait d'un des membres du triangle œdipien.

Dans son dossier 2010, Filigrane veut donc contribuer à une mise à jour de la réflexion sur l'utilisation clinique de la théorie œdipienne. Le temps est-il venu de conceptualiser un ailleurs à l'GEdipe ? Devons-nous considérer une évolution vers une structure autre que sexuelle, «inhumaine ${ }^{1} » 1$ de vie ou encore vers un sujet autofondé et qui aurait tout pouvoir sur les liens qui le fondent? Ou, encore, la théorie œdipienne permet-elle d'étudier de façon satisfaisante les nouveaux conflits psychiques créés par les facilitations contemporaines à la décharge pulsionnelle, les changements survenus dans les repères identitaires construits à partir des différences des sexes et des générations? Bref, quel est l'impact, sur la scène intrapsychique des individus, de l'actuelle évolution, tant technologique que sociale, dans le domaine de la sexualité ?

Telle est la question, difficile mais actuelle, que Filigrane vous demande d'élaborer pour son lectorat à partir de votre expérience clinique.

Date de tombée des textes: $1^{\text {er }}$ septembre 2009; longueur approximative des textes: 15 feuillets; adresse courrielle où faire parvenir le fichier du texte: richard.helene@uqam.ca

le comité de rédaction

\section{Note}

1. Olivier Dyens, 2008, La condition inhumaine, Paris, Flammarion. 